\title{
GARANTIAS JURIDICAS EN LAS HACIENDAS LOCALES*
}

\author{
POR \\ Alfonso PÉrez MORENo \\ Catedrático de Derecho Administrativo \\ de la Universidad de Sevilla
}

\begin{abstract}
Sumario: Planteamiento.-I. Las fuentes reguladoras de las haciendas locales. DE LA SEGURIDAD JURIDICA A LAS INTERPRETACIONES SIN FIN, TRAS LA SENTENCIA DEL TRIBUNAL CONSTITUCIONAL 214/1989, DE 21 DE DICIEMBRE. - II. BASES CONSTITUCIONALES DEL SISTEMA DE GARANTIAS JURIDICO-ADMINISTRATIVAS: A) La garantía del tratamiento común de los administrados. B) Controles sobre el ejercicio de la autonomía local en materia financiera.-III. EL CONTROL DE LA MATERIA ECONÓMICO-ADMINISTRATIVA. TENSION ENTRE LO JUDICIAL Y LO GUBERNATIVO: A) La evolución de las formas de control. B) Legislación posconstitucional sobre Procedimiento Económico-Administrativo. C) El control judicial directo, discriminación real y efectiva de los contribuyentes de la Hacienda local. Sobre la inconstitucionalidad de la supresión de la vía económicoadministrativa. - IV. LAS GARANTIAS ESTABLECIDAS EN LA LEY DE HACIENDAS LOCALES: A) La concreción temporal y las condiciones de la impugnabilidad de las Ordenanzas fiscales. B) Recursos contra la aplicación y efectividad de los tributos locales. Consideraciones sobre la suspensión del acto impugnado. C) La impugnación de Presupuestos locales. D) Sobre la revisión de oficio de los actos económicoadministrativos locales. E) Rectificación de errores $y$ devolución de ingresos indebidos. F) El control y fiscalización de la gestión económica local: 1 . Ambito subjetivo de los controles; 2. La función interventora; 3. El control financiero; 4. El control de eficacia. G) La buena Administración.
\end{abstract}

\section{PLANTEAMIENTO}

El incesante incremento de normas escritas ha merecido a lo largo de este siglo, cuya última década estamos iniciando, toda clase de superlativos y metáforas. Si hace cincuenta años se empleó ya la expresión «legislación motorizada», ahora tendríamos que sustituirla al menos por «legislación supersónica»: tal es el proceso de aceleración de la producción masiva de disposiciones normativas escritas. La tarea de legislar, que naturalmente necesita el sosiego de la reflexión humana, se ve así violentada en su ritmo normal, y, en consecuencia, los resultados de la misma presentan defectos y desarmonías, cuando no contradicciones. En cortos periodos de tiempo se han promulgado leyes con regulaciones distintas de unas mismas cuestiones. Los efectos penelopianos, las ordenaciones en zigzag, las bruscas alteraciones en cualquier sentido de las normas, producen inseguridad jurídica, desuso por invigencia social efectiva y

\footnotetext{
* Este trabajo será publicado en el número 1 de la Revista de Administración de Andalucía.
} 
tentaciones de desobediencia civil. Ante la praxis de tan desenfrenada carrera de normación la doctrina viene abogando por la «desreglamentación» como necesidad liberadora.

En España, la construcción de nuestro modelo de Estado de las Autonomías, junto a los intentos de implantar con vehemencia los nuevos programas políticos, está estimulando todavía más esa masiva recreación urgente de la normativa de las instituciones y relaciones jurídicas, al menos en las páginas de los Boletines Oficiales.

Con el telón de fondo descrito, queremos reflexionar ahora sobre una parcela del ordenamiento jurídico donde las urgencias objetivas nunca han sido oportunamente atendidas por el legislador. Se trata de las Haciendas Locales. La nueva Ley 39/1988, de 28 de diciembre, reguladora de las Haciendas Locales pretende justificar su aplazada promulgación porque en 1985, cuando se pone en marcha la Ley 7/1985, de 2 de abril sobre las Bases del Régimen Local, no estaban conformados definitivamente aspectos de la actividad financiera general de trascendencia en la esfera local: «los aspectos relativos a la estructura del sistema tributario del Estado y a la ordenación de la actividad presupuestaria general».

La Ley viene, pues, a complementar la Ley Básica de 1985 (en adelante $L B R L$ ) dando una regulación acabada a la actividad financiera local. En el diseño de la Ley de Haciendas Locales (en adelante LHL), dicha actividad financiera queda inscrita en el marco jurídico impuesto, como habilitante y legitimador, por el principio de legalidad tan rigurosamente pleno y omnicomprensivo en la materia desde la gestación misma del Estado de Derecho hasta la condensada formulación del artículo 133 de la Constitución de 1978: «1. La potestad originaria para establecer los tributos corresponde exclusivamente al Estado, mediante ley. 2. Las Comunidades Autónomas y las Corporaciones locales podrán establecer y exigir tributos, de acuerdo con la Constitución y las leyes. 3. Todo beneficio fiscal que afecte a los tributos del Estado deberá establecerse en virtud de ley. 4. Las administraciones públicas sólo podrán contraer obligaciones financieras y realizar gastos de acuerdo con las leyes». El marco jurídico en el que queda encuadrada la actividad financiera constituye, pues, la garantía de su "sometimiento pleno a la ley y al Derecho", expresión con la que el artículo 103 de la Norma Suprema concreta para las Administraciones Pública el principio esencial del artículo 9.1: «Los ciudadanos y los poderes públicos están sujetos a la Constitución y al resto del ordenamiento jurídico.»

Ahora bien, la ordenación jurídica de la actividad financiera presenta dos planos de normación nítidamente perceptibles: de una parte, la regulación misma del contenido sustantivo de dicha actividad (los recursos de la Hacienda, el presupuesto y gasto 
público); y de otra, su disciplina jurídica en cuanto es una actuación administrativa sujeta, pues, al ordenamiento jurídico de las Administraciones Públicas. En este segundo plano - que es el que contemplaremos en el presente estudio - cabe a su vez distinguir entre la incidencia del ordenamiento jurídico-administrativo general en la regulación de la Administración hacendística, y el grupo normativo creado por ésta especificado desde la perspectiva de la gestión administrativa de la actividad financiera, según la fértil construcción de la teoría de los grupos normativos de VILLAR PALASi (en Derecho Administrativo. Introducción y teoría de las normas, Madrid, 1968), según la cual «un grupo normativo está constituido por todas las normas jerárquicamente articuladas, que contemplan un mismo supuesto de hecho abstracto, de un modo explícito o implícito, bajo una misma ratio". Cabalmente en la historia de la legislación administrativa tiene una alta significación, como veremos, la gestación de ese grupo normativo específico para la regulación de la actividad administrativa financiera. Las relaciones económicas, privadas o públicas, tienen un gran poder especificante en las instituciones jurídicas: reclaman una normativa propia y separada, aun cuando no sea más que - como sucede en el origen y desarrollo histórico del Derecho Mercantil- una adaptación de soluciones técnicas jurídicas bajo la cúpula de los principios de su Derecho común.

Desde comienzos del siglo XIX la materia económico-administrativa, tan difícilmente deslindable, ha desplegado su poder especificante en el desarrollo de las técnicas jurídico-administrativas, sobre todo en los instrumentos de garantías jurídicas (Vid. SERRERA CONTRERAS: Lo Económico-Administrativo: Historia y Ambito, Instituto García Oviedo, Sevilla, 1966; SANTAMARIA PASTOR: Sobre la génesis del Derecho Administrativo Español en el siglo XIX [1812-1845] en la colección del mismo Instituto, Sevilla, 1973).

En este trabajo trataremos de analizar el grupo normativo de las garantías jurídicas en la LHL, ante el hecho sorprendente de que, en el Derecho posconstitucional, ha sufrido continuos y contradictorios cambios en cortos períodos de tiempo, engendrándose un confuso panorama legislativo que incluso obliga a plantearse la cuestión de su posible inconstitucionalidad.

La exposición de la materia la haremos, tras detenernos en una breve consideración sobre las fuentes reguladoras de las Haciendas Locales, analizando las bases constitucionales del sistema de garantías jurídico-administrativas, para entrar, seguidamente, en el tratamiento legal de las impugnaciones contra la imposición, ordenación y aplicación de tributos, y contra los presupuestos; la regulación de la revisión de oficio y de las técnicas de rectificación; y terminar con una referencia a los controles internos (función interventora, función de control financiero y función de control de eficacia). 
I. LAS FUENTES REGULADORAS DE LAS HACIENDAS LOCALES. DE LA SEGURIDAD JURIDICA A LAS INTERPRETACIONES SIN FIN, TRAS LA SENTENCIA DEL TRIBUNAL CONSTITUCIONAL 214/1989, DE 21 DE DICIEMBRE

La LBRL es una ley ordinaria que se autodefinió como «la norma institucional de los entes locales», y de aquí la consecuencia de que «esa norma desarrolla la garantía constitucional de la autonomía local, función ordinamental que, al estarle reservada, o lo que es igual, vedada a cualesquiera otras normas, presta a su posición en el ordenamiento en su conjunto una vis específica, no obstante su condición formal de Ley Ordinaria» (preámbulo, parte II). Junto a esta fundamentación, cita como título constitucional el artículo 148.1.18. ${ }^{\text {a }}$ en relación con el 148.1.2. ${ }^{\text {a }}$ Por todo ello, en su artículo 5 introdujo una concreción de la prelación de normas aplicables, partiendo de la preferencia de la misma Ley, distinguiendo cinco grupos normativos, correspondiendo el E) a las Haciendas Locales. Quedaba aclarado que éstas se regirían:

«a) Por la legislación general tributaria del Estado y la reguladora de las Haciendas de las entidades locales, de las que será supletoria la Ley General Presupuestaria.

b) Por las Leyes de las Comunidades Autónomas en el marco y de conformidad con la legislación a que se refiere el apartado anterior.

c) Por las Ordenanzas fiscales que dicte la correspondiente entidad local, de acuerdo con lo previsto en esta Ley y en las Leyes mencionadas en los apartados a) y b).»

La función clarificadora del artículo 5 en todos sus apartados era una contribución a la seguridad jurídica, tan amenazada en el conjunto abigarrado de la enorme legislación que produce el Estado compuesto de las Autonomías. Pero, además, en el transcrito apartado E) no ofrece la menor posibilidad de dudas que del «bloque de la constitucionalidad" no puede extraerse otro orden de prelación de fuentes que en el mismo establecido. Sin embargo, el Tribunal Constitucional en Sentencia de 21 de diciembre de 1989 (BOE núm. 10 suplemento, 11 de enero de 1990) ha declarado inconstitucional dicho artículo 5 en su totalidad teniendo en cuenta la siguiente motivación que es la esencia del Fundamento 5:

«Esta argumentación compleja debe ser atendida. EI precepto impugnado establece el orden de prelación de 
normas aplicables a las ditintas materias que conciernen a la Administración Local, situado en primer lugar los contenidos en la propia Ley, que tiene asi efectivamente una pretensión de superioridad ordinamental, que se hace explícita en su exposición de motivos. En cuanto que enumera las normas aplicables en una materia en la que la competencia legislativa está dividida entre el Estado y las Comunidades Autónomas, el precepto ha de ser entendido, en consecuencia, como una norma interpretativa de lo dispuesto en el bloque de la constitucionalidad respecto de esta materia. Es esta naturaleza de norma meramente interpretativa, sin contenido material alguno, la que hace el precepto constitucionalmente ilegítimo.

El orden de fuentes en un ordenamiento compuesto es el establecido por el bloque de la constitucionalidad, sin que uno de los elementos de esta realidad compuesta, en este caso el legislador estatal, pueda imponer a todos los demás, como única interpretación posible, la que él mismo hace. Es cierto que al usar de sus facultades legislativas sobre las materias de su competencia, tanto el Estado como las Comunidades Autónomas han de operar a partir de un determinado entendimiento del bloque de la constitucionalidad. Tal entendimiento, que puede ser también denominado, si se quiere, interpretación, se produce entonces, sin embargo, en conexión con una materia determinada, no como criterio abstracto de interpretación y podrá ser siempre corregido por este Tribunal a través de las oportunas vías procesales.»

Nótese el sustancial paralelismo entre esta Sentencia y la de 5 de agosto de 1983, en relación con los artículos iniciales «interpretativos» de la LOAPA, en la que el Tribunal afirmaba su exclusiva función de intérprete de la Constitución que mereció fundadas críticas doctrinales (MUÑOZ MACHADO, entre otros). A nuestro juicio no podía tacharse al artículo 5 de contener un "criterio abstracto de interpretación» del bloque de la constitucionalidad; por el contrario, los criterios estaban matizados en cinco grupos referido cada uno a materias concretas $y$ enunciadas $\sin$ ambigüedades. Puesto que la seguridad jurídica es un valor garantizado por la Constitución (art. 9.3), bien podría haber sometido ya el Tribunal a su control en esta Sentencia cada una de las determinaciones sobre prelación para contribuir a aquella seguridad manteniendo un artículo 5 depurado, en lo que fuera necesario. Con ello no se obstaculizaba la posibilidad de controles puntuales futuros sobre materias concretas, pero sí se hubiera evitado la incertidumbre expuesta a interpretaciones sin fin, y las 
tentaciones autonómicas para forzar los límites de sus propios ámbitos normativos confiando en que o no se interpondrá recurso de inconstitucionalidad (lo que se presta a ser incluso una complacencia), o se pueda obtener una Sentencia favorable en virtud de criterios de bajos mínimos para la aprobación. En definitiva, no compartimos los razonamientos de la Sentencia ni en este punto, ni tampoco en cuanto a la postergación de potestades locales de autoorganización. El criterio formulado en el voto particular de DIAZ EIMIL nos parece más coherente con el modelo constitucional de la autonomía local, y con el artículo 6.1 de la Carta Europeá de Administración Local (Estrasburgo, 15 de octubre de 1985) vigente en España, tras la rectificación, desde 1 de marzo de 1989. La Sentencia del Tribunal Constitucional no se refiere a ella.

Pero, a los efectos de nuestro tema, hay que señalar que la inconstitucionalidad del artículo 5.E) no elimina de la legislación positiva las determinaciones que contiene por la sencilla razón de que están reiteradas con plenitud ordenadora en diversos artículos de la LHL (arts. 1, 11, 12). El artículo 1 delimita los preceptos sobre sistema tributario local y participación en los tributos estatales, que son ejercicio de la potestad tributaria originaria del Estado (arts. 133 y 142 de la Constitución), y los que tienen la consideración «de bases del Régimen Jurídico Financiero de la Administración Local» (art. 149.1.18. a), añadiendo la cláusula. «sin perjuicio» para dejar citadas las competencias exclusivas del Estado sobre «Hacienda general y Deuda del Estado» (art. 149.1.14. ${ }^{\text {a). }}$

El artículo 12 reenvía a la Ley General Tributaria y «demás leyes del Estado reguladoras de la materia, así como en las disposiciones dictadas para su desarrollo", para la regulación de la gestión, liquidación, inspección y recaudación; a las que el artículo 11 añade el régimen de infracciones y sanciones. Defendimos ya la directa aplicación de la Ley General Tributaria a las Corporaciones Locales en los primeros años de su vigencia (Vid. PEREZ MORENO: «El proceso de penetración de las leyes reguladoras de la Administración Central en el Régimen Local», en Revista de Administración Pública, núm. 61, 1970).

Puntualmente se refiere la Ley a las materias en que pueda operar la legislación de las Comunidades Autónomas. Y regula también con detenimiento las Ordenanzas fiscales como normas jerárquicamente subordinadas, a las que más adelante nos referimos.

Queda, pues, verificado el orden de prelación de fuentes del grupo normativo de las Haciendas Locales, derivado del bloque de la constitucionalidad, en coincidencia con el artículo 5.E) de la Ley BRL. 


\section{BASES CONSTITUCIONALES DEL SISTEMA DE GARANTIAS JURIDICO-ADMINISTRATIVAS}

Para cimentar constitucionalmente las garantías jurídicas de la LHL debemos explorar el artículo 149.1.18. ${ }^{\text {a }}$ y el contenido de la garantía de la autonomía local a los efectos de la compatibilidad de controles sobre su ejercicio. Dos cuestiones sobre las que, en el actual momento de la evolución de la jurisprudencia constitucional y de la doctrina, no cabe abrigar dudas insuperables.

\section{A) La garantía del tratamiento común de los administrados}

Las «bases del régimen jurídico de las Administraciones públicas... que, en todo caso, garantizarán a los administrados un tratamiento común ante ellas", reclaman una legislación estatal que establezca la "regulación normativa uniforme y de vigencia en toda la Nación», "un común denominador normativo" (SS. del T.C. de 28 de enero, 30 de noviembre de 1982, 28 de abril de 1983, 20 de julio de 1984, 22 de marzo de 1988 , etc.) y que comprenda el «núcleo» esencial de la normalización de la materia. Ciertamente el sentido de crear un Derecho estatal general para todo el Estado que deriva de la competencia exclusiva de éste sobre las «Bases», se ve reforzado en este caso desde la perspectiva de la garantía la igualdad de trato de todos los ciudadanos, implícita en el mecanismo de atribución de la legislación básica al Estado, porque se incluye un parámetro material del principio de igualdad: la necesaria garantía a los administrados de un tratamiento común ante las Administraciones públicas. Podría interpretarse que ese tratamiento común se refiere sólo en las Administraciones de las Comunidades Autónomas en relación con la Central del Estado, con lo cual quedarían fuera las Corporaciones Locales. O, en otro sentido, que la Constitución permite dar a los administrados de un tipo de Administraciones públicas, como son las Entidades locales, un tratamiento común aunque no sea igual al establecido para las otras Administraciones superiores. Sin embargo, el carácter sustantivo del parámetro de la igualdad que se garantiza - «tratamiento común»-, y que se refuerza dentro del mismo apartado -aunque los niveles de sus distintas partes no son homogéneos-con «el procedimiento administrativo común» (excepción de las especialidades organizativas de las Comunidades Autónomas); todo ello hace pensar en que no es posible introducir en el régimen jurídico de las Administraciones públicas alteraciones que puedan implicar una desigualdad en el tratamiento de los administrados. Concretando por vía de ejemplo, las posibilidades de los administrados para reaccionar contra los actos administrativos tanto en la vía 
administrativa como en la judicial, tienen que asegurarles un tratamiento común de tal forma que no queda una desigualdad material en la defensa de sus derechos o intereses según la Administración pública con la que se relacione. La expresión «tratamiento común» incluso supera, a nuestro juicio, una mera igualdad formal - que se resolvería en el establecimiento de unas mismas formas de garantía-, y exige la obtención de una igualdad material o efectiva (en la línea del art. 9.2 de la Constitución), cuya consecución puede llegar a determinar la introducción de especialidades de ajuste o correctoras, teniendo en cuenta las diferencias estructurales de los distintos tipos de Administraciones públicas. (Sobre el concpeto «bases» y relación «bases-desarrollo». Vid. MUÑOZ MACHADO: Derecho Público de las Comunidades Autónomas, I, Madrid, 1982; GaRCiA DE ENTERRIA-FERnÁNDEZ RodRigueZ: Curso de Derecho Administrativo, I, Ed. 1989; GONZALEZ NAVARRO: La regla constitucional del «más valer» y el problema de la anomia en Derecho administrativo español, en libro homenaje a Jaime Guasp, Granada, 1984; GOMEZ-FERRER, R.: «Relaciones entre leyes: competencia, jerarquía y función constitucional», en Revista de Administración Pública, núm. 113.)

Finalmente, el control jurisdiccional sobre la Administración encuentra su general apoyo constitucional en el artículo 106.1: «Los Tribunales controlan la potestad reglamentaria y la legalidad de la actuación administrativa, así como el sometimiento de ésta a los fines que la justifican».

\section{B) Controles sobre el ejercicio de la autonomía local en materia financiera}

Tras haber ubicado constitucionalmente el sistema de garantías jurídico-administrativas, hay que hacer una referencia a la cuestión de la pertinencia de los controles administrativos sobre la autonomía local, y, concretamente, sobre los actos que se produzcan en la actividad financiera. El Tribunal Constitucional y la doctrina, incluso partiendo del modelo alemán - tan infielmente tomado como referente por el legislador español (Vid. SOSA WAGNER: «La Autonomía local», en Revista de Estudios de la Administración Local y Autonómica, núms. 239, 240 y 241 , especialmente, el segundo)-, llegan a la conclusión de la compatibilidad de los controles administrativos de legalidad e, incluso, en ciertos supuestos, de oportunidad, sobre el ejercicio de las competencias de las Administraciones locales, pero siempre en virtud de la garantía de los intereses supralocales y con un ámbito limitado y graduado en atención a tipología de las competencias locales. A partir de las Sentencias del TC de 2 y 29 de 
abril de 1981, 28 de junio de 1983, 5 de diciembre de 1984, 27 de febrero de 1987. PAREJO AlFONSO gradúa la intensidad de los controles posibles según que se refieran a competencias propias de las Administraciones locales, les hayan sido transferidas o delegadas, o, simplemente se les haya encomendado la gestión como meros agentes o mandatarios de las de las Administraciones superiores (Estado o Comunidad Autónoma), con las que están en una relación bifronte. Tratándose de las competencias propias, las técnicas limitadas, no genéricas de control comprenden los de legalidad concretados y los de oportunidad puntuales pero suficientes para que la Administración superior pueda preservar $y$ hacer valer los intereses cuya gestión le corresponde (PAREJO ALFONSO: «La Autonomía Local en la Constitución", versión publicada en el Tratado de Derecho Municipal, tomo I, dirigido por Muñoz Machado).

Dentro de este criterio general abierto a la prudente compatibilidad de los controles sobre el ejercicio de la autonomía local, hay que destacar las precisiones del TC sobre la actividad financiera. Ya la Sentencia de 2 de febrero de 1981 puso de relieve la intensidad de las relaciones en dicho campo en los intereses interadministrativos; la profunda conexión directa entre los mismos, estableciendo que «dadas las diversas fuentes que nutren las Haciendas locales, así como su complementariedad, es aquí plenamente aplicable la existencia de controles de legalidad, tanto en relación con la obtención y gestión de ingresos de carácter propio como con la utilización de los procedentes de otras fuentes». Esta fue ya una base interpretativa sólida para mantener el control de los Tribunales económico-administrativos sobre los actos de la Hacienda local.

También, en el plano económico-financiero, el TC en Sentencia de 28 de junio de 1983 estimó procedente el establecimiento de límites a la capacidad de endeudamiento de las Corporaciones locales.

En consecuencia, la autonomía local no impide el establecimiento de controles administrativos sobre los actos producidos en la actividad financiera de las Corporaciones locales.

Dos últimos argumentos refuerzan la conclusión:

- La atención constitucional a las Haciendas locales apunta a que el nivel garantizado no está desconectado de los intereses supralocales. "Las Haciendas locales -ordena el artículo 142 y establece el artículo 105 LBRL- deberán disponer de los medios suficientes para el desempeño de las funciones que la ley atribuye a las Corporaciones respectivas y se nutrirán fundamentalmente de tributos propios y de participación en los del Estado y de las Comunidades Autónomas» (Vid. Sent. TC de 2 de febrero de 1981). Al corresponder exclusivamente al Estado la potestad originaria de establecer los tributos, mediante ley —art. 133-, también pertenecen 
naturalmente al mismo las competencias de supervisar o controlar la ejecución de la legislación (Vid. PAREJo Alfonso: Op. cit., p. 80).

- La referida Carta Europea de Autonomía local precisa en el artículo 8 los siguientes criterios sobre:

«Control administrativo de los actos de las Entidades locales:

1. Todo control administrativo sobre las Entidades locales no puede ser ejercido sino según las formas y en los casos previstos por la Constitución o por Ley.

2. Todo control administrativo de los actos de las Entidades locales no debe normalmente tener como objetivo más que asegurar el respeto a la legalidad y de los principios constitucionales. Sin embargo, tal control podrá extenderse a un control de oportunidad, ejercido por autoridades de nivel superior, respecto de las competencias cuya ejecución se haya delegado en las Entidades locales.

3. El control administrativo de las Entidades locales debe ejercerse manteniendo una proporcionalidad entre la amplitud de la intervención de la autoridad de control y la importancia de los intereses que pretende salvaguardar.»

\section{EL CONTROL DE LA MATERIA ECONOMICO-ADMINISTRATIVA. TENSION ENTRE LO JUDICIAL Y LO GUBERNATIVO}

Antes de llegar a la consideración de lo establecido en el Derecho Local recientemente renovado, es importante otear desde una perspectiva histórica las singularidades de las vías de control de la denominada «materia económico-administrativa». Aunque no esté en el centro de la cuestión que aquí nos interesa, conviene recordar que esa «materia», que ha reclamado para sí un tratamiento propio diferenciado, no ha mantenido confines nítidos.

En otro lugar hemos explicado la carencia de un criterio delimitador - «el incontrable criterio para delimitar la materia económicoadministrativa»- de ese sector de actividad administrativa tan clave para el sostenimiento mismo de la Entidad Pública que la realiza; su carácter previo, medial o instrumental, la dota de una vis resistente al control ajeno a la organización hacendística (PÉREZ MORENO y LOPEZ MENUDO: Comentarios a la Ley General Tributaria, dirigidos por Amorós Rica, tomo II, Madrid, 1983, pp. 596 y ss.). Precisamente los efectos de esa fuerza se manifestaron con viveza en el primer cuarto del siglo XIX mediante el desapoderamiento de todo control judicial. Es importante que nos detengamos en la evolución de esa tensión entre lo judicial y lo gubernativo, que llega a nuestros días aunque, 
paradójicamente, con una mutación en las posiciones interesadas en una u otra forma de control.

\section{A) La evolución de las formas de control}

Al comienzo del siglo XIX los Tribunales ordinarios conocían de las reclamaciones de los contribuyentes. En los años veinte de dicha centuria se va a producir una atribución de la competencia exclusiva de dicho control a órganos administrativos, lo que llevará hasta la creación del confusamente llamado «Tribunal» gubernativo de Hacienda en 1892, manteniéndose hasta nuestros días los Tribunales Económico-Administrativos como órganos administrativos para la resolución de las reclamaciones aunque sólo en la vía administrativa previa a la jurisdicción contencioso-administrativa.

Al comentar, en la obra antes citada, el artículo 163 de la Ley General Tributaria realizamos este desarrollo de la evolución descrita:

La insistente atribución de la competencia exclusiva para conocer de las reclamaciones económico-administrativas a órganos administrativos es uno de los episodios más representativos de la tensión entre lo judicial y lo gubernativo a lo largo del siglo XIX. Frente a las tesis judicialistas que alentaban la praxis de que los tribunales ordinarios entraban en el conocimiento de reclamaciones en materia de contribuciones, se alzó en el trienio 1820-1823 una normativa tendente a «adoptar ciertas medidas para la más pronta y fácil exacción y recaudación de las contribuciones y toda clase de impuestos a los pueblos de la Península». Para ello, el Decreto de 12 de mayo de 1821 desapoderó con un mandato de inhibición a «las Audiencias, Jueces y demás Magistrados», fortaleciendo la competencia directa y exclusiva de los Intendentes. El Decreto de 25 de junio de 1821, que reafirmó el anterior, «instaura - como señala SANTAMARIA PASTOR- el germen de lo que más tarde será la jurisdicción económico-administrativa y contiene una precisión del más alto valor dogmático: la creación de los que llamaremos materias administrativas per se, categoría atípica en la clásica dicotomía gubernativo-contencioso, que será la base material sobre la que veinte años más tarde se construirá el nuevo concepto del contenciosoadministrativo". Por consiguiente, tras el que aparece como precepto meramente organizativo, en las raíces de este artículo 163 se encuentra toda una decisión política fundamental sobre una manera de llevar a la práctica el principio de separación de poderes, en la relación entre Administración y Jurisdicción. Una vez más la peculiaridad de la actividad financiera impone correctivos a los dogmas generales y se convierte en polarizadora de soluciones técnico-jurídicas del Derecho Administrativo. 
Con el fundamento expuesto se explica la reserva administrativa de competencia en el primer tramo del conflicto del contribuyente con la Hacienda, sin perjuicio de la ulterior revisión judicial mediante el recurso contencioso-administrativo al que llega la Administración amparada por el privilegio de decisión ejecutoria (y antes también con la exigencia reforzadora del «solve et repete»). La LGT, heredera de esa tradición jurídica, todavía utiliza la expresión «jurisdicción» económico-administrativa, aunque se reconozca que el procedimiento económico-administrativo tenga naturaleza administrativa al igual que los órganos que lo resuelven. Esta reserva a la Administración de la exclusividad de la competencia frente a los jueces no debió implantarse con facilidad, a juzgar por la aparición de nuevas disposiciones reiterándola, como la Real Orden de 17 de mayo de 1836 y la Orden de Espartero de 31 de enero de 1841 -que destaca SANTAMARIA-, que anuló una serie de providencias dictadas por el juez de Piedrahíta, el cual «admite y conoce de las reclamaciones de los particulares sobre perjuicios por repartimientos de contribuciones».

Conseguida la afirmación de la competencia administrativa (que se explicará ulteriormente como un supuesto de ejercicio de la potestad jurisdiccional de la Administración para agotar la vía administrativa previa a la contencioso-administrativa, artículo 4.2 Reglamento de procedimiento económico-administrativo de 1959), en fecha posterior se introducirá la separación en el Ministerio de Hacienda entre órganos de gestión y órganos de resolución de reclamaciones. Como estudia SERRERA CONTRERAS, el Tribunal gubernativo de Hacienda fue creado por Real Decreto de 29 de diciembre de 1892 con un fin meramente práctico: facilitar, dándole primacía, la gestión tributaria, descargando en otro órgano la ardua tarea de resolver las reclamaciones, y garantizar de esta manera también el sereno estudio de las mismas. Aunque la denominación de «Tribunal» -que se mantendrá hasta nuestros días - induce a la confusión con la Jurisdicción, en las exposiciones de motivos de las primeras normas queda explicitado que la diferenciación orgánica está orientada a separar las funciones activas de la Administración «y las que se han llamado por algunos funciones jurisdiccionales».

Tanto la exclusividad administrativa de la competencia como la peculiar separación en Hacienda entre funciones de gestión y de resolución de reclamaciones, han llegado a la normativa vigente a través del artículo 1 Reglamento de procedimiento económicoadministrativo de 1924 y del artículo 2 Reglamento de procedimiento económico-administrativo de 1959.

(Las citas de SANTAMARIA Y SERRERA se refieren a las obras ya indicadas en el presente trabajo.) 


\section{B) Legislación posconstitucional sobre Procedimiento Económico-Administrativo}

En materia de procedimiento económico-administrativo no es fácil encontrar una época más prolífica en normas que la que va desde 1980 a 1985 . Y dentro de ella se introducirá la contradictoria ruptura del sistema tradicional antes descrito al excluir puntualmente a las Haciendas Locales de la vía económico-administrativa para instaurar radicalmente el control judicial exclusivo. El cambio ha sido tan inmotivado como contradictorio con el primer desarrollo posconstitucional. La sucesión de normas dispares en tan cortos períodos de tiempo presenta un panorama confuso que ha desembocado al fin en la reducción de las garantías efectivas de los ciudadanos contribuyentes a las Haciendas locales, como iremos verificando.

Las principales disposiciones promulgadas sobre la materia en el citado quinquenio son la Ley 39/1980, de 5 de julio, de Bases sobre Procedimiento Económico-Administrativo, el Real Decreto legislativo $2795 / 1980$, de 12 de diciembre, que articuló la anterior Ley; el Real Decreto-ley 3/1981, de 16 de enero; la Ley 40/1981, de 28 de octubre (estas últimas normas urgentes sobre Régimen Local mantuvieron las reclamaciones económico-administrativas en las Haciendas locales, incluso introduciendo la extraña novedad del recurso de alzada ante el TEA Central); el Real Decreto 1999/1981, de 20 de agosto, que aprobó el nuevo Reglamento de Procedimiento en las Reclamaciones Económico-Administrativas; la LBRL (arts. 108, 113 y disposición adicional décima), que suprimió la vía económicoadministrativa en las Corporaciones Locales.

Ya en la doctrina producida en el interregno entre la regulación de urgencia y la nueva Ley Básica se denunció la «ausencia de coordinación prelegislativa por parte del Gobierno" (LOPEZ GONZALEZ: «El nuevo régimen de impugnación de presupuestos y tributos locales", en Revista Española de Derecho Administrativo, núm. 32, 1982). Y, ciertamente, no tiene explicación ni justificación que se haya alterado tan arbitrariamente el nuevo Derecho posconstitucional recién estrenado. La Sentencia del Tribunal Constitucional de 2 de febrero de 1981, como hemos comprobado, respaldaba el control de legalidad sobre la Hacienda local atribuido a los Tribunales EA. Tan sólo para las Comunidades Autónomas la Ley 8/1980, de 22 de septiembre, sobre Financiación, había establecido la novedad de la necesaria creación de "órganos económico-administrativos" propios de las mismas para conocer las reclamaciones contra sus tributos propios (art. 20.1.a). Mantuvo la competencia de los Tribunales Económico-Administrativos estatales para conocer de las reclamaciones cuando se refieren a actos sobre tributos cedidos por el Estado a las Comunidades Autónomas y sobre los recargos establecidos a 
favor de éstas sobre tributos del Estado. A nuestro juicio esta reforma para las Comunidades Autónomas tampoco está justificada (Vid. PEREZ MORENO y LOPEZ MENUdO: Op. cit., p. 585), aunque hay que subrayar que no rompe la estructura del «tratamiento común» de los ciudadanos ante ellas al mantener el mismo esquema de control. Pero a los efectos del enjuiciamiento de la supresión de la vía económico-administrativa en lo local, hay que realzar cómo es ésta la única esfera administrativa en la que se ha producido. Tanto en la Administración del Estado como en la de las Comunidades Autónomas la materia económico-administrativa sigue estando sometida al control de órganos propios separados y especializados para la resolución de las reclamaciones, que actúan, para agotar la vía administrativa previa a la jurisdicción contencioso-administrativa, de forma gratuita $y$, salvo limitadas excepciones, sin necesidad de intervención de Procurador ni de Abogado (art. 38 del Reglamento de 1981).

C) El control judicial directo, discriminación real y efectiva de los contribuyentes de la Hacienda local. Sobre la inconstitucionalidad de la supresión de la vía económico-administrativa

La Ley BRL volvió súbitamente al control judicial directo, sin vía económico-administrativa previa. Y la Ley de $\mathrm{HL}$ lo ha reiterado con el énfasis de una tajante prohibición: "La Jurisdicción ContenciosoAdministrativa -dispone el artículo 14.5 de esta última Ley- será la única competente para dirimir todas las controversias de hecho y de derecho que se susciten entre las Entidades locales y los sujetos pasivos, los responsables y cualquier otro obligado tributario, en relación con las cuestiones a que se refiere la presente Ley».

La rotundidad de la norma y la generalidad de su ámbito, recuerda la estructura del artículo 4 del Reglamento de procedimiento económico-administrativo 1981, que bajo el epígrafe «Exclusividad de la competencia" dispone que los órganos establecidos para la resolución de reclamaciones, separados de los de gestión, son los únicos competentes, con exclusión de cualesquiera otros, para conocer de cuantos procedimientos se sustanciaren en materia económico-administrativa, y que sus resoluciones agotarán la vía administrativa y podrán ser objeto de recurso contenciosoadministrativo.

A la vista de la quiebra ocasionada por la LBRL y LHL en el sistema unificado, por el que se daba a los administrados un tratamiento común en las reclamaciones en materia económico-administrativa, cabe plantear la constitucionalidad de tal excepción.

Ante todo, se nos oculta la extraña arbitrariedad que entraña alterar sin causa un régimen posconstitucional terminado sobre la vía 
económico-administrativa, a escasos años de su vigencia. El grupo normativo queda, en cierta manera, fragmentado con la penetración secante del Derecho local renovado. Cabe aquí plantear si «la función constitucional» atribuida y cumplida por el grupo normativo sobre el Procedimiento económico-administrativo ha sido suplantado inconstitucionalmente por la LBRL, aplicando la doctrina expuesta por GOMEZ-FERRER (Relaciones entre leyes..., op. cit.).

Ahondado en las motivaciones profundas del legislador, y despejada ya la objeción del respeto a la autonomía local, parece más bien que se trata de dificultar el control de los actos económico-administrativos locales, aunque se deje abierto el cauce jurisdiccional. Verdaderamente la supresión de la vía económico-administrativa previa, como de la de la vía administrativa en general, es una propuesta progresiva de la doctrina, y con razón se ha celebrado su eliminación a los efectos del acceso a la Protección Jurisdiccional de los Derechos fundamentales. Sólo con desazón pueden recordarse los tiempos en los que no estaba establecido el silencio en el procedimiento económico-administrativo y había que esperar años hasta que se producian las obligadas resoluciones expresas. La acumulación de asuntos -especialmente cuando a raíz de reformas fiscales sustantivas crecen las dudas interpretativas - convierte en servidumbre frecuentemente inútil la larga demora de las resoluciones. Por consiguiente, si tratáramos de enjuiciar la cuestión desde esta perspectiva, habría que celebrar ese comienzo de eliminación de las trabas impuestas por la potestad jurisdiccional de la Administración. Pero sucede que la supresión radical de la vía económico-administrativa priva al administrado en las Corporaciones Locales de medios de garantía que rompen el "tratamiento común» ordenado por la Constitución. Para interponer recurso contencioso-administrativo es necesario, ante todo, valerse de Procurador y Abogado. Muchos actos económico-administrativos, especialmente los que se realizan en masa, son de escasa cuantía, y por regla general superarían los gastos del proceso el importe de las cuotas tributarias. La vía jurisdiccional directa inhibe a un altísimo porcentaje de contribuyentes.

Por el contrario, la vía económico-administrativa en materia local, además de tener la ventaja de la gratuidad, ofrece también las de la especialización y el distanciamiento y separación del órgano que resuelve las reclamaciones. Los Tribunales económico-administrativos no son, por así decir, jueces en su propia causa /nemo iudex in causa sua); aunque no pueda atribuírseles de manera absoluta la nota de imparcialidad, es más probable que impregne realmente más su funcionamiento que tratándose de reclamaciones contra actos de la Hacienda estatal. Todo este conjunto de notas - a las que debe añadirse la colegialidad y la unificación de doctrina- avalan la tesis de que existen razones de fondo en el tratamiento que dispensa la 
existencia de la vía económico-administrativa a los administrados, como para considerar que su supresión engendra una desigualdad dañosa para aquellos a los que se prohíbe utilizarla.

Desde esta perspectiva es posible considerar inconstitucional la supresión radical de la vía económico-administrativa en la Hacienda local. Los contribuyentes tienen abierta esa vía en todas las Administraciones públicas menos en las Entidades locales. No es superflua su utilización en el contexto real en que se desarrolla el sistema de garantías porque un gran número de administrados tendrán que acudir a ella como única para ellos más efectiva. Luego la consecuencia obligada es que debe restablecerse, aunque sea sólo con carácter potestativo.

La solución propuesta, a la vez que se ajusta a la Constitución, ofrece la ventaja adicional nada desdeñable de frenar el desorbitado incremento súbito de procesos contencioso-administrativos en materia fiscal; reducirlos en el futuro, al quedar muchas cuestiones resueltas en vía económico-administrativa; y mantener una unificación de criterios interpretativos porque los Tribunales Superiores de Justicia revisarán las resoluciones de los Tribunales administrativos. La reimplantación de dicha vía, obviamente, sólo es posible mediante ley estatal que modifique la LBRL y la LHL, ambas reservadas a la competencia legislativa del Estado, y vedadas a las Comunidades Autónomas.

\section{LAS GARANTIAS ESTABLECIDAS EN LA LEY DE HACIENDAS LOCALES}

Advertidos ya de la opción de la LHL por el control judicial directo, previo el recurso de reposición, importa, sin embargo, proceder analíticamente siguiendo las distintas fases en las que se manifiesta la actividad económico-financiera local: 1) la imposición y ordenación de tributos; 2) la aplicación y efectividad de los mismos; 3) la aprobación de los Presupuestos. Finalmente, trataremos, por encuadrarse genéricamente dentro de la técnica de control, de la revisión de oficio de los actos económico-administrativos, la rectificación de errores y la devolución de los ingresos indebidos; y haremos una referencia a las funciones de control interno de la gestión económica: función interventora, función de control financiero y función de control de eficacia.

\section{A) La concreción temporal y las condiciones de la impugnabilidad de las Ordenanzas fiscales}

Los Ayuntamientos tienen que acordar la imposición de los tributos propios, que establece la $\mathrm{LHL}$, a excepción de los tres 
impuestos directamente implantados por la misma: Impuesto sobre Bienes Inmuebles, Impuesto sobre Actividades Económicas e Impuesto sobre Vehículos de Tracción Mecánica (art. 60). Aun en éstos, pueden hacer uso de las facultades legales para fijar elementos necesarios para la determinación de las cuotas tributarias. En todo caso, al tiempo de acordar la imposición o de fijar los elementos, deberán aprobar las Ordenanzas fiscales, con el detallado contenido fijado por la LHL (art. 16). Minuciosamente se regulan las fases del procedimiento de aprobación, que comprende la adopción del acuerdo provisional, la exposición al público durante un mínimo de treinta días o -con difusión en el Boletín Oficial de la provincia y en las Entidades de más de 10.000 habitantes en un diario de mayor difusión-, y aprobación definitiva, que no será necesaria si no se presentan reclamaciones. Estos trámites se ajustan a la regulación de la LBRL (arts. 49, 70, 106 y 107), pero la disposición adicional primera de la LHL se ha visto obligada a reformar los artículos 107.1 y 111 de aquella Ley. Las Ordenanzas entrarán en vigor a partir de su íntegra publicación sin que tengan que hacerlo simultáneamente con el presupuesto del ejercicio económico siguiente a la aprobación de aquéllas; y sin que haya que esperar al plazo establecido en el requerimiento de anulación que formulen las Administraciones estatal o de la Comunidad Autónoma por infracción del ordenamiento jurídico (art. 65.2 LBRL). A los efectos de nuestro estudio interesa destacar:

a) Que, aparte de la obligada edición de las Ordenanzas en general para las Entidades locales de más de 20.000 habitantes, todas están obligadas a expedir copias de las mismas a quienes las demanden. Se superará así las frecuentes dificultades de los administrados para conseguir los textos de las mismas.

b) Que queda reconocida en el artículo 18 de la LHL la condición de interesados, además de a los que tuvieran un interés directo o que resulten afectados, a «los Colegios Oficiales, Cámaras Oficiales, Asociaciones y demás Entidades legalmente constituidas para velar por los intereses profesionales, económicos o vecinales, cuando actúen en defensa de los que les son propias».

c) Que el artículo 19 permite precisar algunas cuestiones importantes concernientes a la impugnación:

1. Deroga la posibilidad que se mantenía sobre la base del artículo 219.2 del Reglamento de Haciendas Locales de poder impugnar los acuerdos de imposición y las Ordenanzas no sólo en el momento de su aprobación, sino en los ejercicios sucesivos durante el plazo en que figure expuesto al público el presupuesto en que las exacciones a que se referían figuraban incluidas. A propósito del entonces artículo 99 del Proyecto de la Ley Básica de R. L. LOPEZ GONZALEZ (El nuevo régimen de impugnación..., op. cit., pp. 821 y 
834), puso de manifiesto la abundante jurisprudencia sostenedora de la vía del citado artículo 219: «Se trata de conceder así -en expresión de la Sentencia de 11 de febrero de 1977- una nueva oportunidad para revisar la legalidad de las exacciones, pues lo contrario produciría indefensión jurídica a los contribuyentes que lo fueran por primera vez y conduciría, además, al absurdo inevitable de la vigencia de imposiciones manifiestamente opuestas a la Ley por el hecho de haber pasado - quizás - inadvertida su ilegalidad en el ejercicio de su establecimiento y creación». Y concluía el citado autor sosteniendo: «De llegar a aprobarse, el artículo 99 del Proyecto protagonizaría sin duda alguna una importante restricción al vigente régimen de impugnación de acuerdos locales sobre imposición y ordenación de tributos, con el consiguiente detrimento de las garantías de los contribuyentes».

El artículo 19 de la LHL suprime claramente esa vía al disponer que las Ordenanzas fiscales «regirán durante el plazo, determinado o indefinido, previsto en las mismas, sin que quepa contra ellas otro recurso que el contencioso-administrativo que se podrá interponer, a partir de la publicación en el "Boletín Oficial" de la provincia o, en su caso, de la Comunidad Autónoma uniprovincial, en la forma y plazos que establezcan las normas reguladoras de dicha Jurisdicción». Por consiguiente, no quedará otro remedio en el futuro contra la Ordenanza ilegal no recurrida que la aplicación de la vía de excepción, regulada en el artículo 6 de la Ley Orgánica del Poder Judicial «Los Jueces y Tribunales no aplicarán los reglamentos o cualquier otra disposición contrarios a la Constitución, a la ley o al principio de jerarquía normativa»), o la impugnación indirecta a través del acto de aplicación conforme a la técnica general del artículo 39, párrafos 2 y 4 de la Ley de la Jurisdicción Contencioso-Administrativa; con la consecuencia de que, en ambos remedios el Tribunal no puede declarar la nulidad erga omnes de la disposición ilegal, sino tan sólo tener en cuenta dicha ilegalidad a los efectos de la anulación del acto administrativo recurrido.

2. El artículo $19 \mathrm{LHL}$ resuelve también las dudas suscitadas sobre la procedencia del recurso de reposición previo al contenciosoadministrativo contra las Ordenanzas fiscales. Esas dudas nacieron de la contradicción entre los artículos 108 y 113 de la LBRL; el primero estableció el recurso de reposición previo contra los actos de aplicación y efectividad de los tributos locales, mientras que el segundo dispuso, confusamente, que contra los actos que pongan fin a las reclamaciones formuladas en relación con los acuerdos sobre presupuestos, imposición, aplicación y efectividad de tributos, o aprobación y modificación de Ordenanzas fiscales, los interesados podrán interponer directamente el recurso contencioso-administrativo. 
Las expresiones «podrá» y «podrán interponer directamente» suscitaban la duda de si el recurso de reposición era potestativo contra los actos de aplicación, y si quedaba eliminado contra las Ordenanzas. GONZALEZ PÉREZ (Régimen jurídico de la Administración Local, Abella, 1985 , p. 438) entendió que la interpretación más correcta era que quedaba excluida la vía económico-administrativa, pero que deberían seguirse las reglas generales sobre el recurso de reposición previo a la jurisdiccional. Sin embargo, la actual redacción del artículo 19.1 de la LHL es categórica: no cabrán contra las Ordenanzas fiscales «otro recurso que el contencioso-administrativo", añadiendo que los plazos se cuentan a partir de la publicación oficial de aquéllas, lo que deja ratificado el mandato de imposible utilización del recurso de reposición. Queda así derogado el artículo 211.2 del Reglamento OF y Régimen Jurídico de 28 de noviembre de 1986 que estableció el carácter potestativo del recurso.

3. Finalmente, el artículo 19.2 permite recordar la vigencia del singular e importante artículo 85 de la Ley de la Jurisdicción Contencioso-Administrativa, que ordena que los fallos anulatorios que se dicten en materia de Ordenanzas fiscales «deberán expresar concretamente la forma en que han de quedar redactados los preceptos impugnados». Efectivamente, el precepto de la LHL en estudio parte del supuesto de hecho de que por virtud de resolución judicial resultare anulado o modoficado el texto de las Ordenanzas fiscales, y para tal evento ordena a là Corporación que publique, con la misma solemnidad que el texto inicial, «bien la anulación, bien la nueva redacción de los preceptos modificados conforme a la resolución correspondiente».

\section{B) Recursos contra la aplicación y efectividad de los tributos locales. Consideraciones sobre la suspensión del acto impug- nado}

La LHL se remite al artículo 108 de la LBRL reiterando que contra los actos sobre aplicación y efectividad de los tributos locales podrá formularse recurso de reposición previo al contencioso-administrativo en el plazo de un mes (art. 14.4). De esta manera se incorporan dichos actos al conjunto común de todos los actos administrativos locales, respecto de los que el recurso de reposición es preceptivo (arts. 52 y ss. de la Ley de la Jurisdicción CA). En este sentido poco añade el precepto al contenido del artículo 192 del Texto Refundido de 18 de abril de 1986.

Sin embargo, en el centro de gravedad de tan extenso artículo, que se refiere a la suspensión de los actos recurridos, sí introduce la nueva regulación innovaciones importantes. Mantiene la exclusión de la regla "solve et repete»: efectivamente, para interponer el 
recurso de reposición no se requerirá el previo pago de la deuda tributaria. Pero también formula la regla general de que la interposición del recurso «no detendrá, en ningún caso, la acción administrativa para la cobranza». Ahora bien la excepción a la regla queda ya categorizada con el efecto de la suspensión preceptiva no discrecional; excepción que sigue siendo que se solicite la suspensión dentro del mismo plazo de interposición del recurso y acompañando «garantía que cubra el total de la deuda tributaria». Si se cumplen esos requisitos - petición dentro del mes acompañada de una de las garantías tipificadas por la Ley-entonces «se otorgará la suspensión instada»; expresión que añade expresamente el artículo 14, inexistente en el 192 del Texto Refundido.

Junto a estos supuestos de suspensión preceptiva, se siguen admitiendo otros excepcionales y de otorgamiento discrecional, en los que no se exigirá prestación de garantía: «cuando el recurrente alegue $y$ justifique en su solicitud la imposibilidad de prestarla $0-y$ este añadido sí es nuevo- demuestre fehacientemente la existencia de errores materiales o aritméticos en los actos sobre aplicación y efectividad de los tributos locales». El artículo $14 \mathrm{LHL}$ retoca también las formas de garantía a elección del recurrente y añade la efianza provisional y solidaria prestada por dos contribuyentes de la localidad de reconocida solvencia, sólo para débitos inferiores a 100.000 pesetas".

Por último, el precepto establece que la suspensión lleva aparejada la obligación de satisfacer intereses de demora por todo el tiempo de aquélla y que sólo producirá efectos en el recurso de reposición.

A la vista del cualificado régimen especial de estas suspensiones se nos suscitan algunas cuestiones e inquietudes generales, que vamos a considerar sucintamente:

a) Existe una desarmonía entre el plazo para el pago voluntario de las deudas tributarias (art. 20 del Reglamento General de Recaudación: las notificadas entre los días 1 y 15 de cada mes, hasta el día 5 del mes siguiente; y las notificadas entre los días 16 y último de cada mes, hasta el día 20 del siguiente) y el plazo del mes para pedir la suspensión simultáneamente o no, con el recurso de reposición. Por ello si el administrado quiere adquirir seguridad de que no expirará el período voluntario de pago tendrá que anticipar la petición de suspensión. Creemos posible, pues, que esta petición sea independiente y anticipada, anunciándolo, al recurso de reposición, aunque lo normal sea que se realicen conjuntamente, y aun en el mismo escrito.

b) Que la suspensión sólo produzca efectos en el recurso de reposición puede crear dificultades y cargas al administrador, sin beneficio alguno para la Administración, aunque sí para la Entidad avalista. 
Hay que distinguir varios supuestos. Si el recurso de reposición se desestimara expresamente, entonces con la resolución del mismo deberá la Administración devolver el aval o el depósito con la advertencia de que se levanta la suspensión. En tal caso, el interesado podrá interponer el recurso contencioso-administrativo y pedir la suspensión al Tribunal, que al otorgarla, exigirá la prestación de caución; en la práctica ello le obliga a constituir un nuevo aval. Pero si la Administración no resuelve el recurso de reposición y el interesado se ve obligado a iniciar el contencioso-administrativo contra el silencio -hipótesis, por desgracia, bien frecuente-, entonces creemos admisible, puesto que la Administración retendrá el aval, que la entidad avalista reconozca ante la Sala la continuidad del aval anterior pero referido desde la suspensión judicial a la caución establecida por el Tribunal bajo cuyo control quedará. Este puede requerir a la Administración para que presente el documento original del aval inicial superando así la indefensión que pueda estar padeciendo el recurrente al que aquélla niegue la devolución del aval primitivo. La tendencia de la jurisprudencia a extender a la vía judicial las flexibilidades de las suspensiones en materia fiscal establecidas en la vía administrativa de recurso de reposición, se expresan en el Auto del TS de 15 de abril de 1989 -que estimó recurso de apelación contra el que denegara una suspensión de liquidación de Impuesto local- en estos términos:

«El número 2 del artículo 122 de la Ley Jurisdiccional que determina que procederá la suspensión de la ejecución de los actos administrativos en la vía del recurso contenciosoadministrativo, a instancias del actor, cuando tal ejecución hubiere de ocasionar daños o perjuicios de reparación imposible o difícil, ha de ser aplicado a la luz de la interpretación que del mismo hace la Exposición de Motivos de tal Ley, según la cual, al juzgar sobre la procedencia de la suspensión se debe ponderar, ante todo, la medida en que el interés público exija la ejecución para otorgar la suspensión con mayor o menor amplitud, según el grado en que el interés público esté en juego, sin que pueda excluirse la dificultad de la reparación por la circunstancia de que el daño o perjuicio que podría derivar de la ejecución sea valorable económicamente. $Y$ de la necesidad de la ponderación de los intereses en juego y teniendo en cuenta que el legislador en el campo de las liquidaciones tributarias, tanto en el ámbito estatal como local, considera suficiente para la protección del interés público implicado en la suspensión de la ejecución de aquellas que el importe de las mismas y sus intereses estén suficientemente garantizados..., ha de llegarse a la conclusión 
de que, también, en vía jurisdiccional ha de estimarse suficientemente protegido el interés público cuando la Administración tenga garantizado el importe y los intereses de demora de las liquidaciones tributarias, la suspensión de cuya ejecución, a instancia del actor, puede decretarse aunque supeditada a la efectiva prestación de la garantía que cubra aquéllos.»

c) Sorprende que la demostración fehaciente de un error material o aritmético en el acto tributario tan sólo dé lugar a la suspensión del mismo. Es lógico pensar que se trata de una medida cautelar, y que el asunto quedará a la espera de que lo resuelva favorablemente el órgano competente. Sin embargo, hubiera sido más garantizador permitir en tales supuestos la aplicación de otra técnica que, a nuestro juicio, podría ser la suspensión de la notificación del acto, como si se tratara de una devolución del mismo por cualquier otra causa, aunque en este caso sería previa constancia de la demostración fehaciente del error.

d) Otra cuestión importante es la indemnización en caso de que sea estimado el recurso.

Ya nos consta que la suspensión determina la obligación de pagar intereses de demora a la Administración, si se confirma la validez y eficacia del acto. Pero en caso contrario, ¿qué derecho tiene el administrado a ser resarcido de los daños? La Ley 39/1980, de 5 de julio de Bases sobre Procedimiento Económico-Administrativo, Base 3. ${ }^{\text {b }}$, y el artículo 36 del Texto Articulado de 12 de diciembre de 1980 , y el artículo 115, Cuatro del Reglamento de 1981, establecen que si, estimada la reclamación, se hubiera de devolver al interesado cantidades ingresadas tendrá derecho al interés de demora desde la fecha del ingreso y conforme al artículo 36.2 de la Ley General Presupuestaria. Nada se dice sobre los gastos efectuados en las garantías para la suspensión. Parece construible la solución de que dichos gastos debieran ser indemnizados, y de que se extienda el tratamiento a los reclamantes frente a las Haciendas locales.

e) Finalmente es cuestionable si la suspensión debe extenderse a la totalidad de la deuda tributaria, y si podría sustituirse el sistema por otra técnica en la que quedará más protegido el interés general, como podría ser dividiendo al 50 por 100 la deuda tributaria sujetando una parte a ejecución inmediata y la otra a suspensión pura y simple (Vid. LOPEZ MENUDO: Op. cit., p. 565).

Expuestas las consideraciones que anteceden, terminaremos este punto aludiendo a la conveniencia de que se crearan soluciones de organización internas en las Corporaciones con más posibilidades para agilizar las resoluciones expresas de los recursos de reposición (art. 69 LBRL); y que, las Diputaciones establecieran la asistencia 
precisa a fin de cooperar con los Ayuntamientos creando un instrumento eficaz de asesoramiento que permitiera resolver los recursos de reposición, evitando paralizaciones, descoordinación de criterios interpretativos, $y$, en fin, el incremento de litigios en la materia fiscal. En definitiva las suspensiones no favorecen ni al Ente local ni al administrado, únicamente a las entidades de crédito por el cúmulo de avales.

\section{C) La impugnación de Presupuestos locales}

El procedimiento para la aprobación del Presupuesto General, que no está sometido a intervención ni a ningún tipo de control, establece como participación ciudadana el trámite de exposición pública por quince días. Aprobado definitivamente debe remitirse una copia a las Administraciones del Estado y de la Comunidad Autónoma. Hasta la finalización definitiva del ejercicio deberá hallarse a disposición del público una copia del Presupuesto a efectos informativos (art. 150 LHL). Se amplía el concepto de interesados a los efectos de reclamar contra los Presupuestos locales, pues además de los afectados y los Colegios, Cámaras, Sindicatos, Asociaciones y demás Entidades creadas para velar por los intereses de su grupo, se incluyen «los habitantes en el territorio de la respectiva Entidad local» (art. 151 LHL).

Contra la aprobación definitiva podrá interponerse directamente recurso contencioso-administrativo. Con dicho término vuelve a plantear el artículo 152 la cuestión de si se excluye el recurso de reposición. A nuestro juicio hay que estimar que sí lo suprime, porque aunque añade «en la forma y plazos que establecen las normas de dicha jurisdicción», no puede entenderse en esta expresión comprendido el recurso de reposición como trámite preprocesal. La redacción del precepto no deja lugar a dudas de la intención de suprimir la reposición; quizás porque el legislador considere que el interesado -al igual que en las Ordenanzas fiscales- ya ha podido someter el asunto al conocimiento de la Administración en la reclamación previa.

Junto con este criterio interpretativo hay que recordar la coincidencia con el artículo 113 de la LBRL; y sobre todo, que el artículo 52 de esta última Ley ya dejó reconocida la existencia de actos contra los que no procederá el recurso de reposición, ni como preceptivo ni como potestativo: "Contra los actos y acuerdos de las entidades locales que pongan fin a la vía administrativa - dispone en el párrafo 1 -, los interesados podrán, previo recurso de reposición, en los casos que proceda, ejercer las acciones que procedan ante la Jurisdicción competente.» Una primera lectura del precepto -que de forma tan redundante emplea el verbo «proceder»- hace pensar que 
sólo se excluiría el recurso de reposición en aquellos casos en que se trate de acuerdos que ponen fin a la vía administrativa previa a las jurisdicciones civil y laboral. Pero, entendemos que hay que considerar que también se refiere a aquellos actos o acuerdos que expresamente estableza la ley que se impugnarán directamente mediante recurso contencioso-administrativo. Estas consideraciones se refuerzan en el conjunto de la $\mathrm{LHL}$, en la que se deja claramente establecido cuándo procede y cuándo no procede el recurso de reposición. Quedan así superados los intentos del Reglamento OF y Régimen Jurídico de 28 de noviembre de 1986 (art. 211.2) por aclarar la materia declarando que el recurso de reposición sería potestativo en materia de presupuestos, imposición y ordenación de tributos.

\section{D) Sobre la revisión de oficio de los actos económico-administrativos locales}

Tan matizado estaba el artículo 5 de la LBRL -declarado inconstitucional por la ya comentada Sentencia del TC de 21 de diciembre de 1989-, que, aunque en el apartado C) reenviaba la regulación del procedimiento administrativo a la Ley General Estatal; sin embargo, en el D) se remitió a la Ley General Tributaria en cuanto a las Haciendas Locales. Y, además, su artículo 110 atribuye al Pleno de la Corporación la declaración de nulidad y la revisión de los actos dictados en la vía de gestión tributaria, siguiendo los artículos 153 y 154 de la Ley General Tributaria en cuanto a casos y procedimiento; remitiendo "los demás casos" en los que deba procederse a la revisión a la declaración de lesividad.

La LHL en este punto tan sólo establece que «se estará a lo dispuesto en el artículo 110" de la LBRL. No se introduce ninguna especialidad en la materia.

El artículo 153 LGT regula la declaración, de oficio o a instancia de parte, de la nulidad de los actos en los mismos casos previstos en el artículo 109 de la Ley de Procedimiento Administrativo, salvo que se excluye el supuesto de actos de contenido imposible, y se exige expresamente la audiencia de «aquellos a cuyo favor reconoció derechos el acto", por supuesto derivable del artículo 91 LPA (realzado por el artículo 105 de la Constitución). Al ser preceptivo el dictamen del Consejo de Estado - aunque el artículo 153 no añade que deba ser «favorable»-, conviene recordar que el artículo 48 de la LBRL ordena que la petición se curse «por conducto del Presidente de la Comunidad Autónoma y a través del Ministerio de Administración Territorial».

Más significativas son las facilidades que otorga el artículo 154 LGT para la revisión, sin declaración de lesividad, de los actos de gestión tributaria: 
a) Se amplía el plazo al referirlo al tiempo de la prescripción, que es de cinco años.

b) Se suprime la necesidad de que el Consejo de Estado dictamine que el acto infringe manifiestamente la ley; basta sólo con la audiencia del interesado.

c) Se admite la posibilidad de revisión también «cuando se aporten nuevas pruebas que acrediten elementos del hecho imponible íntegramente ignorados por la Administración al dictar el acto objeto de revisión».

Las fundadas críticas de la doctrina a estas vías revisorias iniciadas, sólo para los casos de manifiesta ilegalidad, en el artículo 110.2 de la Ley de Procedimiento Administrativo, deben ampliarse en relación con el artículo 154 LGT. A nuestro juicio hay que recordar e insistir en su carácter de norma excepcional frente a la contenida en el artículo 159 de la misma Ley, que consagra la irrevocabilidad de los actos, salvo que la revocación sea mediante la declaración de lesividad. Por eso, la jurisprudencia que interpreta restrictivamente los supuestos del artículo 110.2 LPA, debe aplicarse a la interpretación del artículo 154 LGT. Es importante en esta línea la Sentencia del TS de 4 de enero de 1983 (Aranzadi 2229), que llega a considerar renunciable por la Administración la vía del artículo 110.2 para seguir el procedimiento de lesividad de menos prerrogativas y que ofrece más ventajas al administrado (Vid. SANTAMARIA PASTOR y PAREJO ALFONSO: Derecho Administrativo. La jurisprudencia del Tribunal Supremo, Madrid, 1989, p. 381, en este punto redactado por Chinchilla Marín).

\section{E) Rectificación de errores y devolución de ingresos indebidos}

El artículo 14.2 de la LHL hace un reenvío recepticio a los artículos 155 y 156 de la Ley General Tributaria para regular, respectivamente, devolución de ingresos indebidos y la rectificación de errores materiales y de hecho. La nueva redacción del párrafo primero del artículo 155 (Ley 10/1985, de 28 de abril), le ha incorporado la aplicación del interés legal.

La rectificación de errores sigue teniendo la singularidad del límite temporal impuesto por el plazo de prescripción, por lo que sólo es posible «siempre que no hubieren transcurrido cinco años desde que se dictó el acto objeto de rectificación».

La Ley General Tributaria, en su artículo 157, somete todas las resoluciones revisoras y rectificadoras a la reclamación económicoadministrativas. En puridad ni la LHL, ni la LBRL han matizado que en esos supuestos tampoco será posible seguir dicha vía; sin embargo, 
los términos categóricos y generales del artículo 14.5 de la LHL permiten concluir que en los mismos procederá aplicar la regla general del recurso de reposición previo al contenciosoadministrativo.

\section{F) El control y fiscalización de la gestión económica local}

El título VI de la LHL, sobre Presupuesto y gasto público, finaliza con un capítulo dedicado a la regulación del control interno de la gestión económica y de la fiscalización externa de las cuentas y de dicha gestión. Esta última se resuelve mediante el reenvío a la Ley Orgánica del Tribunal de Cuentas y su Ley de Funcionamiento (art. 204).

Pero el control interno es objeto de una amplia y novedosa regulación en la Hacienda local, y puesto que está adquiriendo gran desarrollo y significación real en la vida de las Entidades locales, consideramos muy conveniente el análisis de la ordenación jurídica de dicho control.

Es de consulta obligada el punto VI de la Exposición de Motivos de la LHL porque explica la evolución, los propósitos de la reforma y las técnicas presupuestarias, contables y fiscalizadoras que se proyectan para alcanzarlo. El objetivo legal es acercar el régimen presupuestario y contable de las Entidades locales, "al máximo posible», a los preceptos de la Ley General Presupuestaria. Precisamente, dos meses antes de la LHL se había publicado el Texto Refundido de aquella Ley, aprobado por el Real Decreto legislativo 1091/1988, de 23 de septiembre, en cuyo artículo 17 se incorporó la elaboración del plan anual de auditorías que estableciera la Disposición adicional 15 de la Ley 44/1983, de 28 de diciembre.

La Exposición de Motivos de la LHL, tras describir la superación a partir de la LBRL del distanciamiento anterior entre los comportamientos de las Hacienda local y la del Estado, concluye presentando las nuevas vías de control en estos términos clarificadores: «En cuanto a la fiscalización en las Corporaciones locales, venía centrada hasta ahora en el llamado control de legalidad, ignorándose prácticamente, los otros controles que, incluso por precepto constitucional, son exigibles en las Administraciones Públicas. De ahí la necesidad, como la Ley lo hace, de regular no sólo el control interno en su faceta interventora, sino también en sus acepciones de control financiero y control de eficacia.»

Y, efectivamente, el artículo 194 LHL somete la gestión económica de las Entidades locales, de los Organismos Autónomos y de las Sociedades Mercantiles de ellos dependientes, a control interno «en su triple acepción de función interventora, función de control financiero y función de control de eficacia», que pasamos a analizar. 


\section{AMBITO SUBJETIVO DE LOS CONTROLES}

Se someten al control a las Entidades Locales, sus Organismos Autónomos y las Sociedades Mercantiles de ellas dependientes. En el Texto de la Ley General Presupuestaria refiriéndose al Estado, además de las anteriores, añade «y demás Entes públicos estatales, cualquiera que sea su denominación y forma jurídica», con lo que se trata de englobar a las instituciones atípicas crónicamente persistentes en la esfera estatal, y prácticamente inexistentes en la local.

\section{LA FUNCION INTERVENTORA}

El nuevo régimen jurídico matiza una variedad de modalidades de ejercicio de esta función (arts. 193 y 200 LHL).

La técnica que expresa el resultado negativo de la función interventora es la formulación de reparos por escrito. Pero sus efectos son distintos según la naturaleza del expediente (art. 197):

- Si se refiere al reconocimiento de derechos a favor de la Entidad, la nota de reparo no suspenderá el expediente.

- Si afecta a disposición de gastos, reconocimiento de obligaciones u ordenación de pagos, suspenderá el expediente sólo en cuatro casos:

«a) Cuando se base en la insuficiencia de crédito o el propuesto no sea adecuado.

b) Cuando no hubieran sido fiscalizados los actos que dieron origen a las órdenes de pago.

c) En los casos de omisión en el expediente de requisitos o trámites esenciales.

d) Cuando el reparo derive de comprobaciones materiales de obras, suministros, adquisiciones y servicios."

Corresponde al Presidente de la Entidad local, sin posibilidad de delegación, resolver en el supuesto de que el órgano de gestión no esté conforme con el reparo, salvo en dos supuestos que la competencia es del Pleno: que el reparo se hubiera basado en insuficiencia o inadecuación de crédito, o que la aprobación de las obligaciones o del gasto corresponda al Pleno. En todo caso este supremo órgano colegiado conocerá de los informes que debe elevarle el órgano interventor sobre los casos en que el Presidente ha resuelto en contra de los reparos y sobre las anomalías detectadas en los ingresos (art. 199).

\section{El CONTROL FINANCIERO}

Este control se define desde una perspectiva global finalista como la comprobación del funcionamiento en el aspecto económico- 
financiero de las Entidades controladas; $y$, de forma descriptiva, como verificación de «la adecuada presentación de la información financiera, del cumplimiento de las normas y directrices que sean de aplicación y del grado de eficacia y eficiencia en la consecución de los objetivos previstos» (art. 201). El mismo artículo contiene un mandato sobre el método a seguir: debe realizarse por procedimientos de auditoría según las normas ya vigentes para el Sector Público.

La técnica establecida para la expresión de este control es el informe escrito. Si el órgano auditado formulara alegaciones, se remitirán con dicho informe al Pleno para su examen.

\section{EL CONTROL DE EFICACIA}

Esta modalidad de control está muy escasamente regulada, aunque el artículo 202 LHL sigue el mismo contenido sustancial del artículo 17.2 de la Ley General Presupuestaria.

El objeto del control de eficacia queda al menos enunciado - «la comprobación periódica del grado de cumplimiento de los objetivos, así como el análisis del coste de funcionamiento y del rendimiento de los respectivos servicios o inversiones»-, pero en cambio nada se establece sobre el método de elaboración y expresión.

En general los efectos últimos de los resultados de los controles no quedan decididos por el legislador. Es difícil, además, crear unas consecuencias distintas a las que resultarán del debate en el Pleno. Habría que pensar en la conversión de las conclusiones de estos controles internos económico financieros en magnitudes propias del control de legalidad: nulidad, anulabilidad, revocación y, consecuentemente, responsabilidades.

\section{G) La buena Administración}

Se ha puesto tanto el acento en el concepto subjetivo de Administración Pública, y en la vinculación por el principio de legalidad, que, a veces, parece admitirse implícitamente que la adecuación de la actuación administrativa a la ley es ya un fin legitimador global. La realidad es muy otra, como lo demuestra la constitucionalización del mandato de eficacia (art. 103.1 de la Norma Suprema). La buena Administración tiene, pues, que ser fruto de la unión de una Administración ajustada a Derecho que, a la vez, consigue una administración eficaz, sirviendo lo más plenamente posible, y al menor coste, con objetividad, los intereses generales. Esta buena gestión administrativa es un resultado en el que sí interviene el contenido de la legalidad, pero también las directrices, la selección de programas, tiempos y métodos; y todo ello es un 
producto de la acción de la dosis derivada del juego del pluralismo político que conlleva la autonomía local.

El artículo 3 de la Ley de Contratos del Estado invoca con pleno carácter normativo «los principios de buena administración». Y de esta y otras normas, como las que venimos comentando, cabe inducirlos como elemento integrante del ordenamiento jurídicoadministrativo, y cuyo quebranto no genere sólo la censura o la responsabilidad política. En este sentido hay que recordar el artículo 78 de la LBRL, y debemos proponer un desarrollo de los controles hasta dotarlos de efectos jurídicos precisos. 
